\title{
The effect of sodium restriction on iodine prophylaxis: a review
}

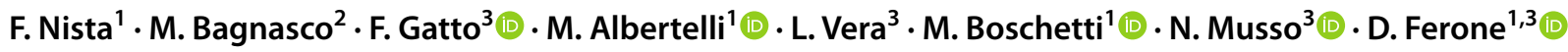

Received: 20 December 2021 / Accepted: 16 January 2022

(C) Italian Society of Endocrinology (SIE) 2022

\begin{abstract}
Purpose Sodium is essential to life. However, its dietary excess is detrimental to the cardiovascular system, and sodium restriction is a crucial step in cardiovascular prevention. Iodine deficiency has been fought worldwide for decades, and substantial success has been achieved introducing the use of iodine-enriched salt. Nevertheless, areas of iodine deficiency persist around the world, both in developing and industrialized countries, and a major concern affecting dietary sodium reduction programs is represented by a possible iodine intake deficiency. There are substantial differences in the source of alimentary iodine among countries, such as iodized salt added, household tap water, seafood, or salt employed in packaged food. It is clear that a sodium-restricted diet can induce differences in terms of iodine intake, depending on the country considered. Moreover, iodine status has undergone relevant changes in many countries in the last years.

Methods Systematic review of literature evidence about the possible effects of sodium restriction on population iodine status. Results To date, the available results are conflicting, depending on country, salt iodization policy, as well as time frame of data collection. However, to ensure an optimal iodine supply by salt fortification, without exceeding the current recommendation by World Health Organization for salt intake, seems to be an achievable goal.

Conclusion A balanced approach may be obtained by an adequate iodine concentration in fortified salt and by promoting the availability of iodized salt for household consumption and food industry use. In this scenario, updated prospective studies are strongly needed.
\end{abstract}

Keywords Iodine $\cdot$ Salt $\cdot$ Sodium $\cdot$ Iodine deficiency $\cdot$ Sodium restriction

\section{Introduction}

Dietary sodium restriction represents the standard nonpharmacological approach to hypertension [1-5]. Sodium, the main source of which is table salt, is a primary nutrient essential to life. However, its excess is detrimental to the cardiovascular system [6-8], and high salt consumption is associated with hypertension, as well as increased prevalence

F. Gatto

fedgatto@hotmail.it; federico.gatto@hsanmartino.it

1 Endocrinology Unit, Department of Internal Medicine and Center of Excellence for Biomedical Research, University of Genoa, Genoa, Italy

2 Department of Internal Medicine and Medical Specialties, President-elect of the Italian Thyroid Association, University of Genoa, Genoa, Italy

3 Endocrinology Unit, IRCCS Ospedale Policlinico San Martino, 16132 Genoa, Italy of cardiovascular diseases [5]. On the other hand, sodium reduction is crucial for cardiovascular prevention [1-4].

Nevertheless, the effectiveness and the safety of dietary sodium reduction in the general population are still debated [9-12]. Iodine deficiency, in contrast, is a definite basic trouble for humans since millions of years [13]. Iodine is essential to the thyroid function. Furthermore, iodine deficiency not only affects the thyroid physiology itself, but also causes growth and neurodevelopment retardation, as well as neurologic and cognitive deficits in children. Since the beginning of the last century, first in the US [14], iodine supplementation has been undertaken by law, with the addition of sodium iodide to table salt. In the following decades, iodine deficiency has been fought relentlessly worldwide, and substantial success has been achieved [15]. Nevertheless, iodine deficiency still persists around the world, in both developed and developing countries [16]. Despite the first law dates to the middle 1920s, being approximately onehundred-year old, a nation-wide salt iodization program in Italy has been implemented only at the beginning of the 
twenty-first century [17]. Noteworthy, iodine sufficiency (IS) appears worldwide a fragile condition [18]: the main concern affecting dietary sodium restriction programs is indeed represented by a possible iodine intake deficiency [19]. The evaluation of iodine status did not show homogeneous data in hypertensive patients under low sodium diet $[20,21]$. Urinary iodine excretion (UIE), based on 24-h urinary collections, iodine/creatinine excretion ratio, or spot morning urine sampling, is the most widely used biomarker to assess the IS, but it is worth underlining that it reflects the recent dietary intake of iodine, as it can change depending upon daily iodine intake [22]. In order to overcome the inter- and intra-individual variation of urine iodine concentration, it is crucial to manage large sample size in order to estimate the real iodine status [23-29].

Areas of iodine deficiency are still present around the world, both in developed economies and in low- and middle-income countries [30]. The main difference among geographical regions relies on the source of alimentary iodine, such as fortified salt added during cooking or at the table, household tap water, seafood, or salt employed by the food industry [31]. It seems clear that a low sodium diet, involving a restriction of added salt, or preserved and packaged foods, can induce large differences in terms of iodine intake, depending on the country observed.

The present review aims to evaluate by literature search the available evidence about the possible impairment of iodine prophylaxis programs due to dietary salt reduction in the population.

\section{Materials and methods}

A systematic review of the literature on Web of Knowledge (ISI, Clarivate ${ }^{\mathrm{TM}}$ ), PubMed/Medline (NIH/NLM), and Scopus (@2021 Elsevier) databases was performed with the keywords "diet or intake", "restriction or reduction", "iodine status", "iodine sufficiency or deficiency", and "sodium or salt". Usual Boolean operators linked the terms employed. Search results ranged from 1928 to November 2021. The Preferred Reporting Items for Systematic Reviews and Meta-Analyses (PRISMA) Statement guidelines were followed [32] and 1347 results were analyzed. Research papers, clinical trials, letters, and reviews in English language or at least with an abstract in English language published in journals with a certified impact factor (IF), or at least appearing in two different databases were selected. Furthermore, duplicates, anecdotal reports, and, where possible, editorials, as well as personal opinions were discarded. After the initial restrictions were applied, 350 papers were screened and, among these, 198 manuscripts were excluded because they were outside the scope of this review. Overall, 152 fulltext articles were assessed for eligibility and were analyzed independently by two author teams. A third author discussed and resolved the controversies and only the papers selected by both teams were considered for the present review. A total of 76 citations were finally selected, the oldest dating to 1928 . Selection criteria included manuscripts concerning dietary advice/education/habit, food analysis, iodine intake, iodine excretion, iodine status, salt consumption, sodium excretion, and dietary sodium restriction/reduction. Then, a quantitative analysis was performed, and 13 papers [20, 27, 33-43] (7 population studies [20, 34, 35, 38, 41-43], 3 studies based on a simulation model [33, 36, 37], 2 randomized controlled trials (RCTs) [27, 40], 1 cohort study [39]) presented both inclusion criteria and relevant results to be discussed considering the aim of the present review. In detail, studies involving highly selected categories such as pregnant women (at higher risk of both iodine deficiency and hypertension), and articles not dealing with iodized salt or made in countries not using it (for example, South Korea), were not considered. Reports with inconsistencies in the description of the study design and/or their results were also excluded. Furthermore, studies based on populations undergoing special diets were not recorded, except for one analysis dealing with a Paleolithic-type diet [13] (included in the discussion but not in the results). In addition to the selected papers, publications by the World Health Organization (WHO), by the Iodine Global Network (IGN) websites, and guideline citations have been included. Finally, the website of the Italian Ministry of Health has been cited, as well. The flow diagram reporting study identification, screening and inclusion is depicted in Fig. 1.

\section{Results}

The main characteristics of the 13 studies that have been analyzed in detail (i.e., country, time of data collection, iodine content of iodized salt) are summarized in Table 1. As shown, these studies have been performed in distinct epidemiological settings and in countries applying different programs in terms of both lowering sodium consumption and promoting iodine supplementation among the population. Moreover, data have been recorded over a large time span. In each country, the beginning of initiatives undertaken to promote salt iodization, without increasing salt consumption, should be taken into account. Specifically, the time of data collection (from 1997 to nowadays) rather than the publication years has been considered.

As shown in Table 1, out of the 13 papers selected, 7 were population-based studies, 3 simulation studies, 2 RCTs and 1 a cohort study. Based on the study design and the number of subjects involved, 3 population studies [20, 42, 43], 2 simulation studies [33, 36] and one RCT [27] may be classified as high-quality studies in the present review. 
Fig. 1 Preferred Reporting Items for Systematic Reviews and Meta-Analyses (PRISMA) 2009 flow diagram selection of the literature search from PubMed. The papers were sorted on the basis of the inclusion and exclusion criteria detailed in the manuscript. Modified from Moher D, Liberati A, Tetzlaff J, Altman DG, The PRISMA Group (2009) Preferred Reporting Items for Systematic The PRISMA Statement. PLoS Med 6(7): e1000097. https:// doi.org/10.1371/journal.pmed. 1000097 Reviews and Meta-Analyses:
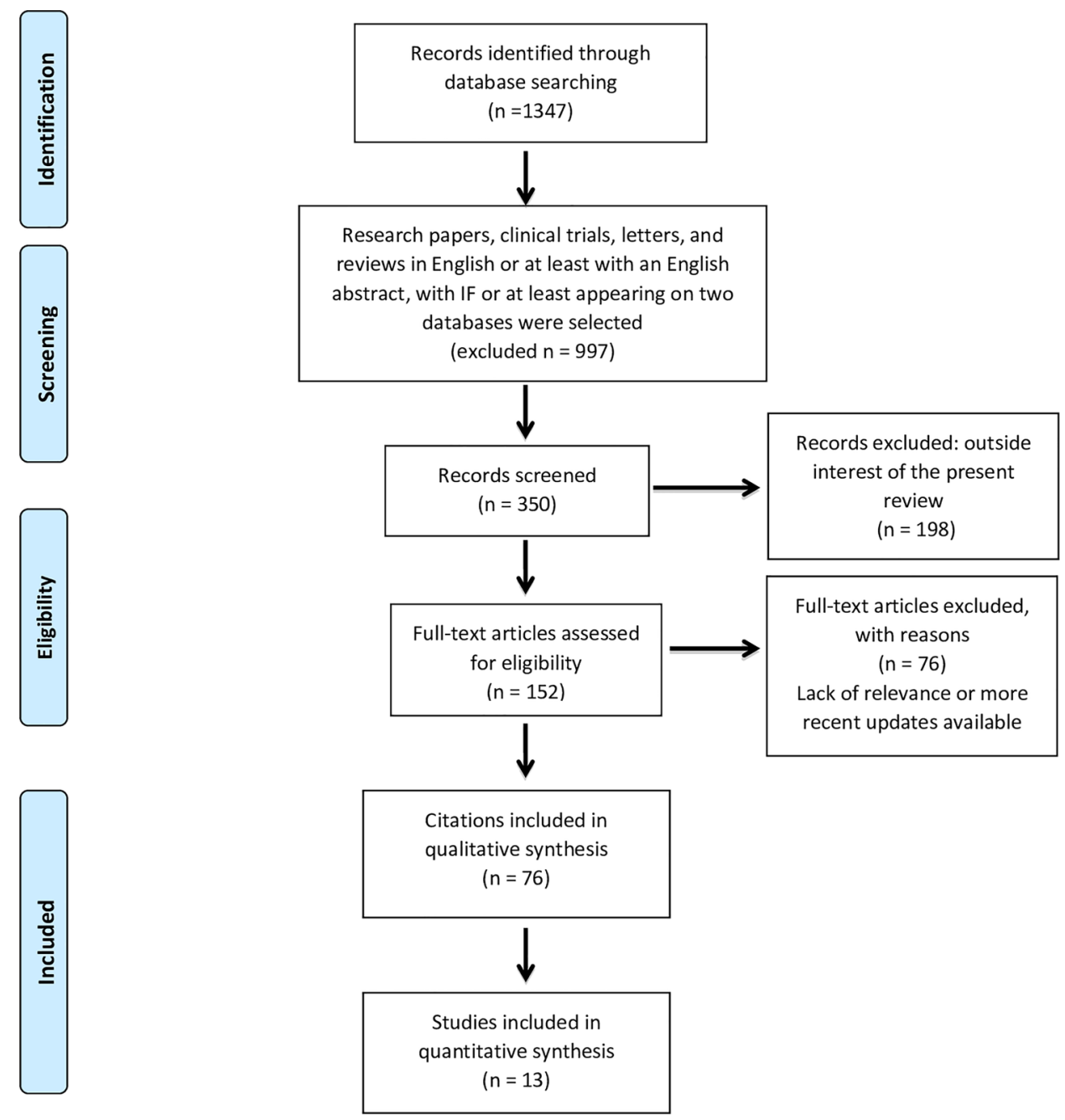

Out of 13 studies assessed, 12 aimed to directly evaluate whether a low sodium dietary intake could affect the iodine status. With all the above-mentioned limitations affecting a direct comparison of the different studies, 3 manuscripts identified a possible link between a lower sodium intake and an increased prevalence of iodine deficiency. In detail, this connection was observed in Italian children and adolescents [41] and in the population of North European regions [33, 42]. Conversely, 9 studies did not find a worsening in the iodine status in the setting of low sodium intake. These results were obtained in the US population [20], in Italian adults [36, 39], in a post hoc analysis of a Dutch study [40], in adults and children living in Northern China [27], in Australia (especially in Native Australians) [35, 37], and among South African and Ghanaian adults [34, 43]. In one manuscript evaluating young women in Samoa [38], no relationship was found between urinary sodium and iodine excretion, but it has to be highlighted that in the Pacific region the level of salt consumption (iodized and non-iodized) is largely unknown, and data on iodine nutrition are sparse. It is worth noting that in the three studies [33, 41, 42] in which lower sodium intake resulted in inadequate iodine supply, iodine status at the baseline was suboptimal. Moreover, in two of these studies, iodine concentration in table salt was as low as $20 \mathrm{mg}$ iodine $/ \mathrm{kg}$ salt.

\section{Discussion}

Iodine deficiency is as old as the humankind [13]. Nowadays areas of iodine deficiency still persist around the world, despite many nationwide supplementation programs [14-17].

Iodine consumption is generally assessed by urinary iodine concentration, especially with spot urine samples (due to the greater feasibility), with 24-h urinary collection, or using the iodine/creatinine ratio. More heavily than sodium, iodine intake shows a high daily inter- and intra-variability, therefore it is crucial to collect large sample size in population studies to estimate the real iodine status [23-29]. 


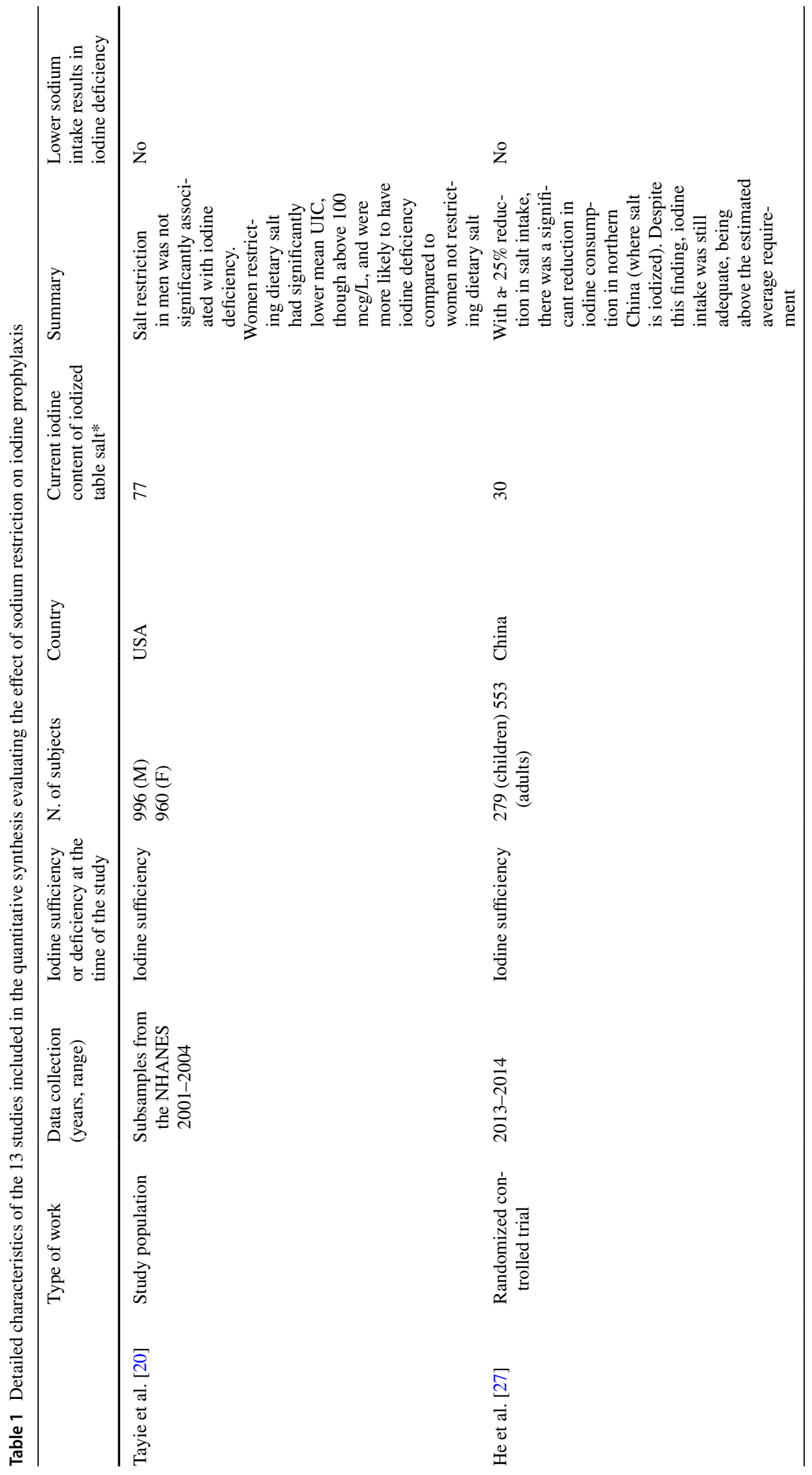




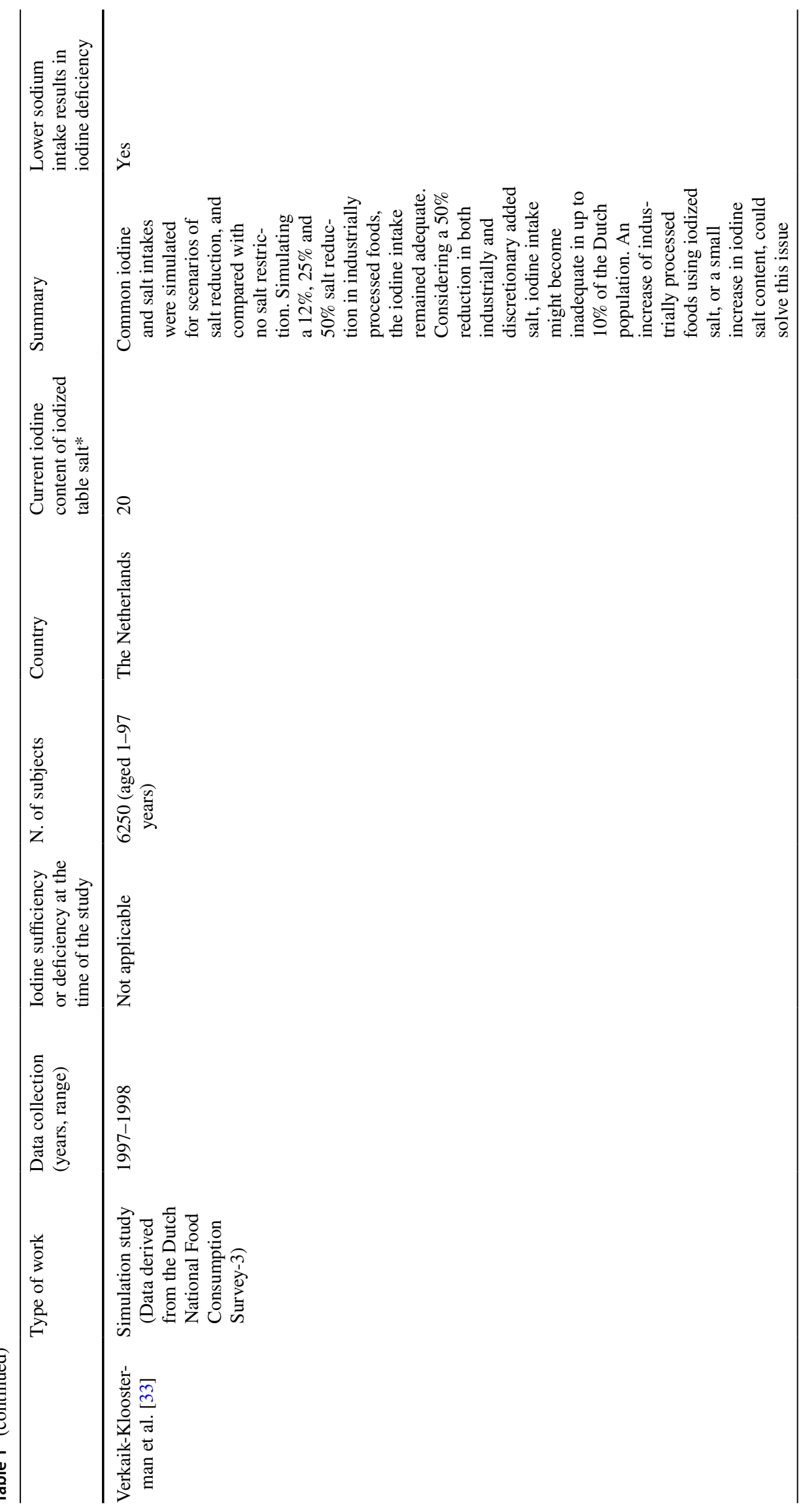




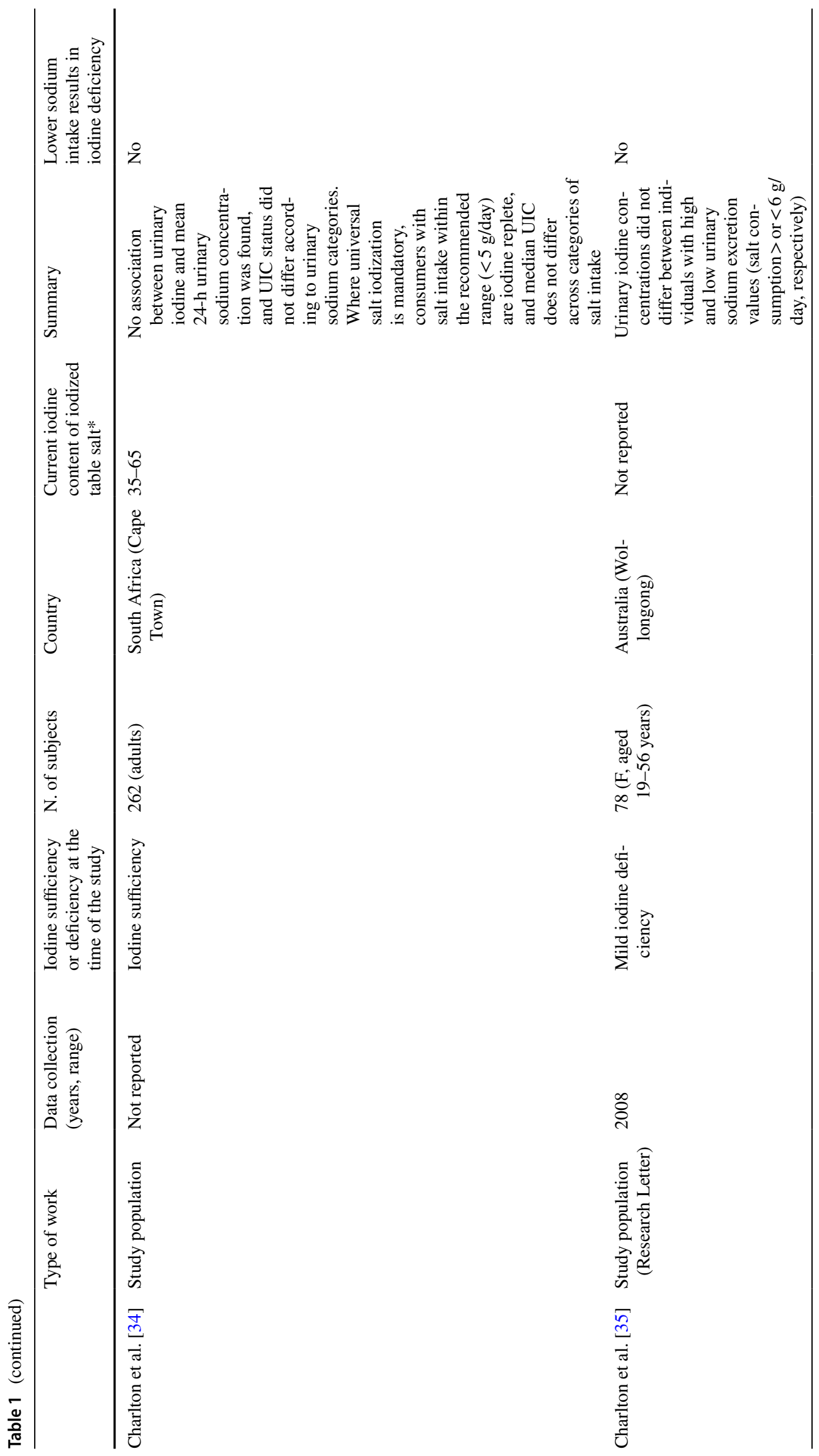




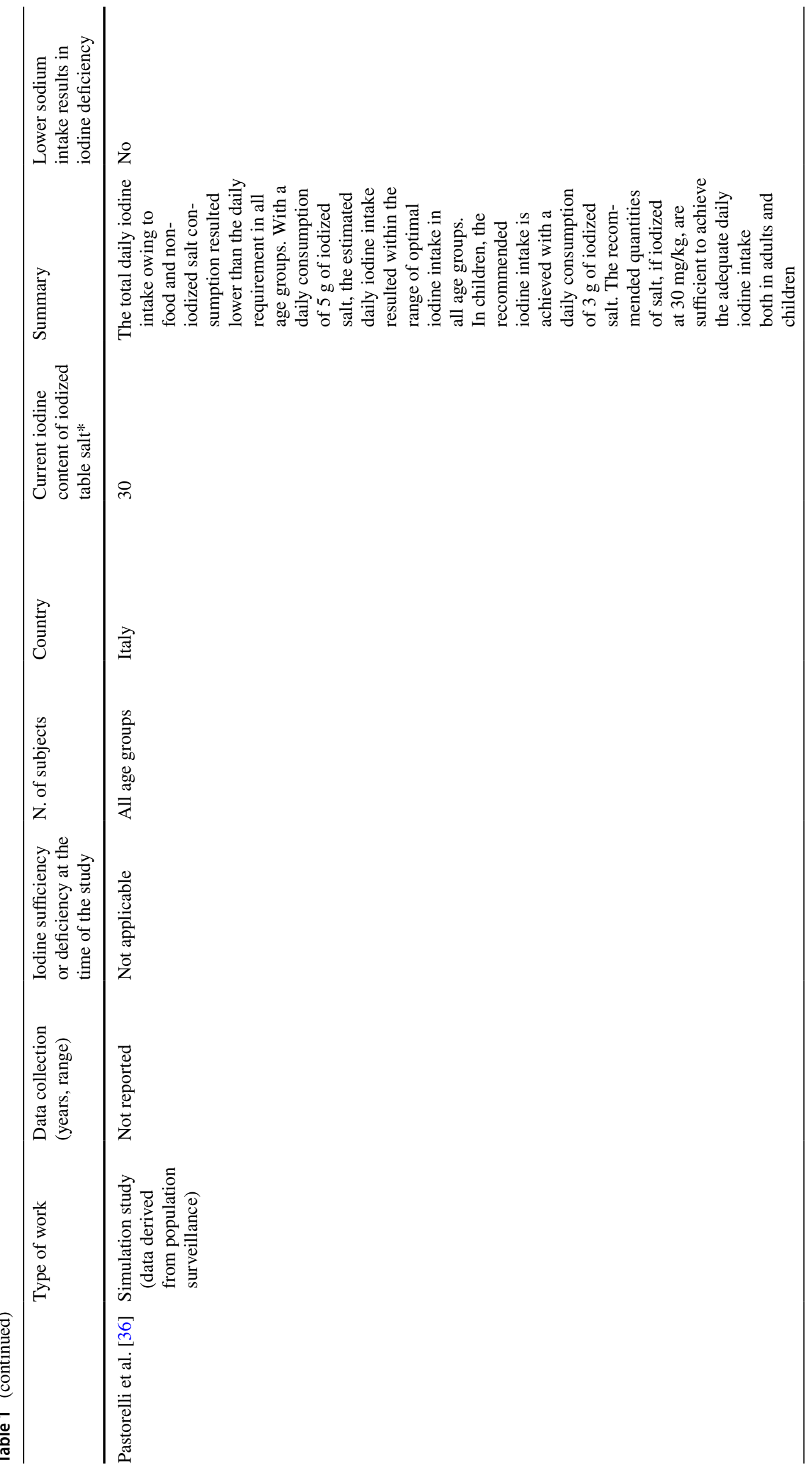




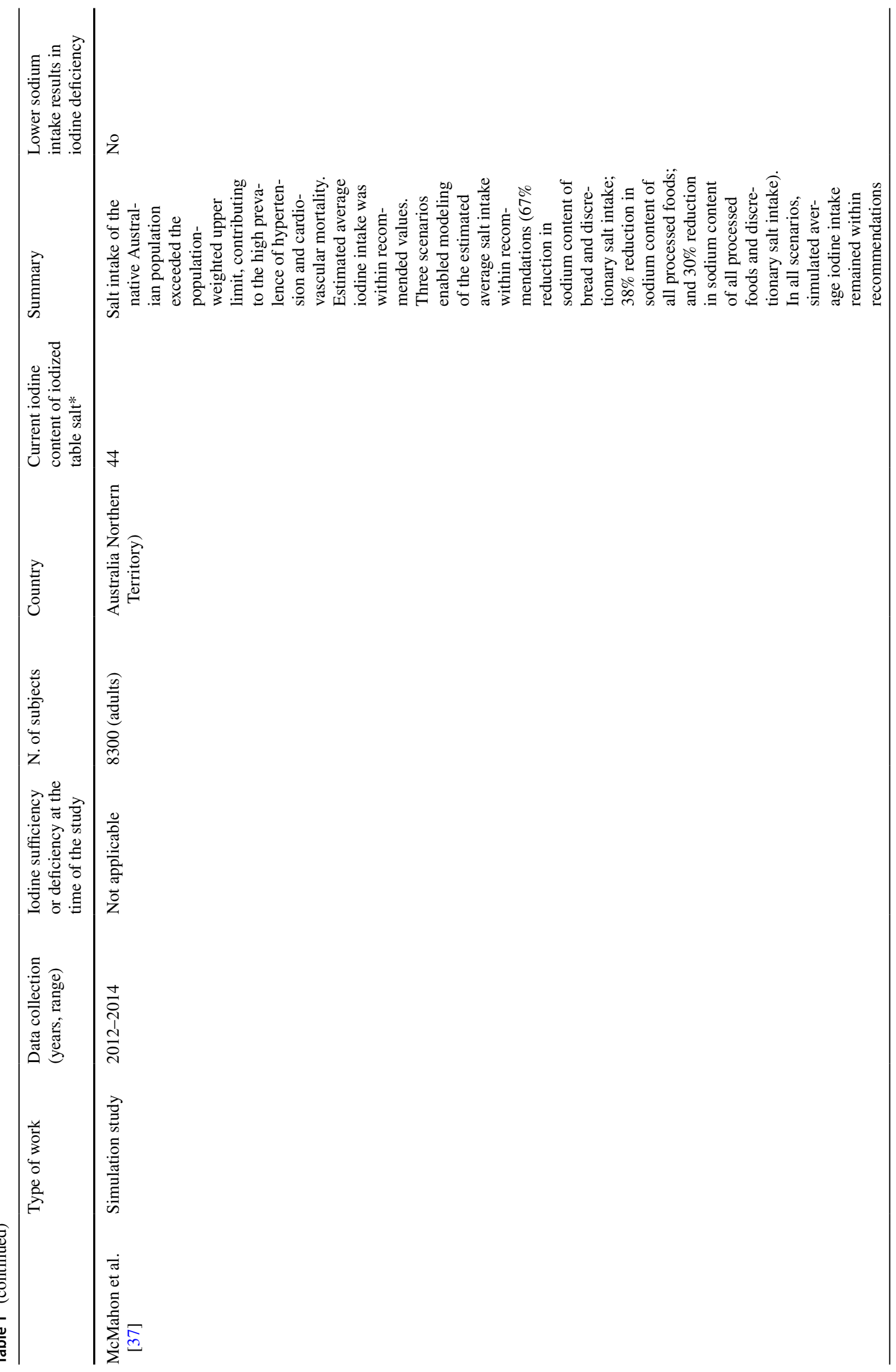




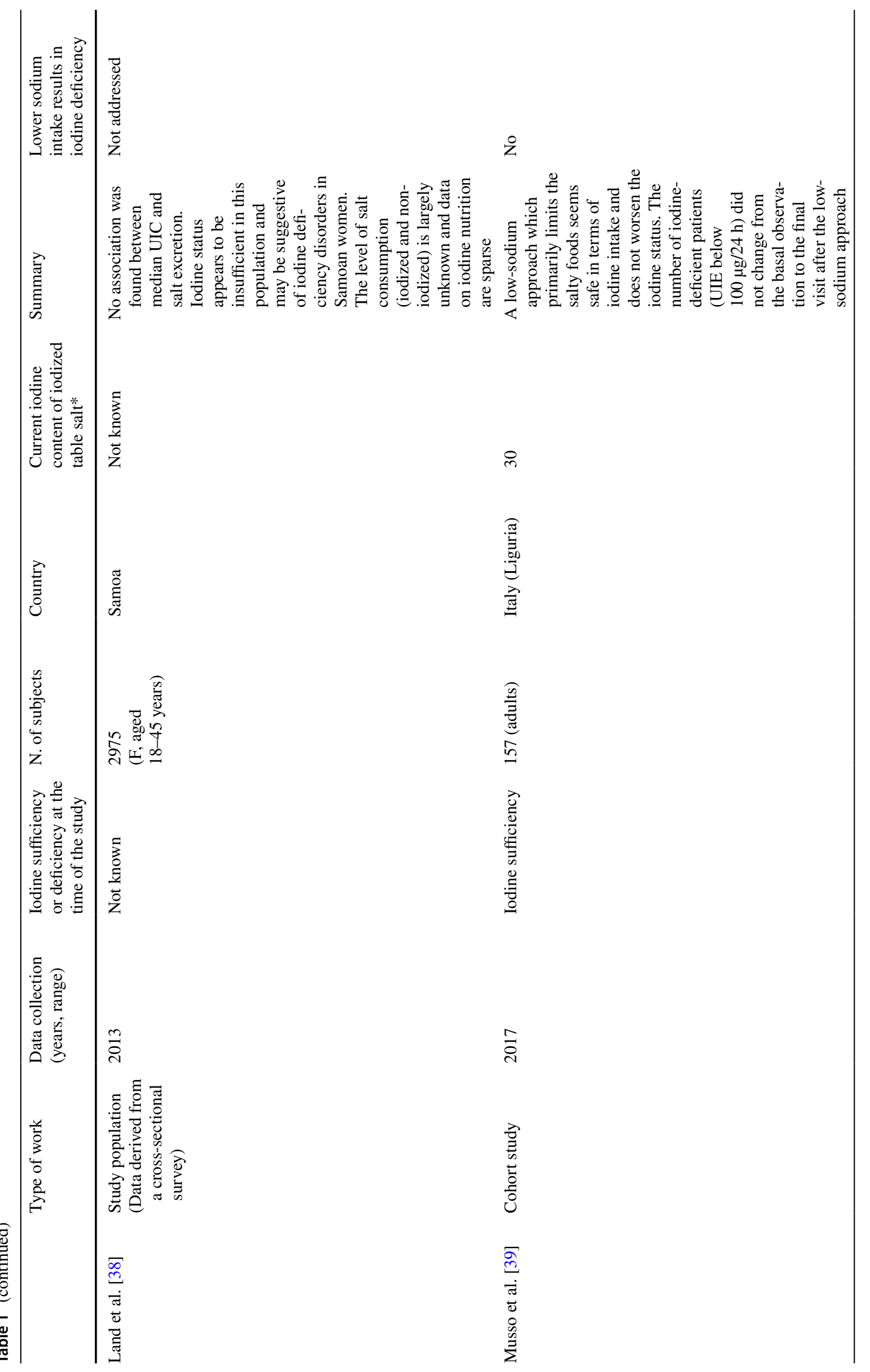




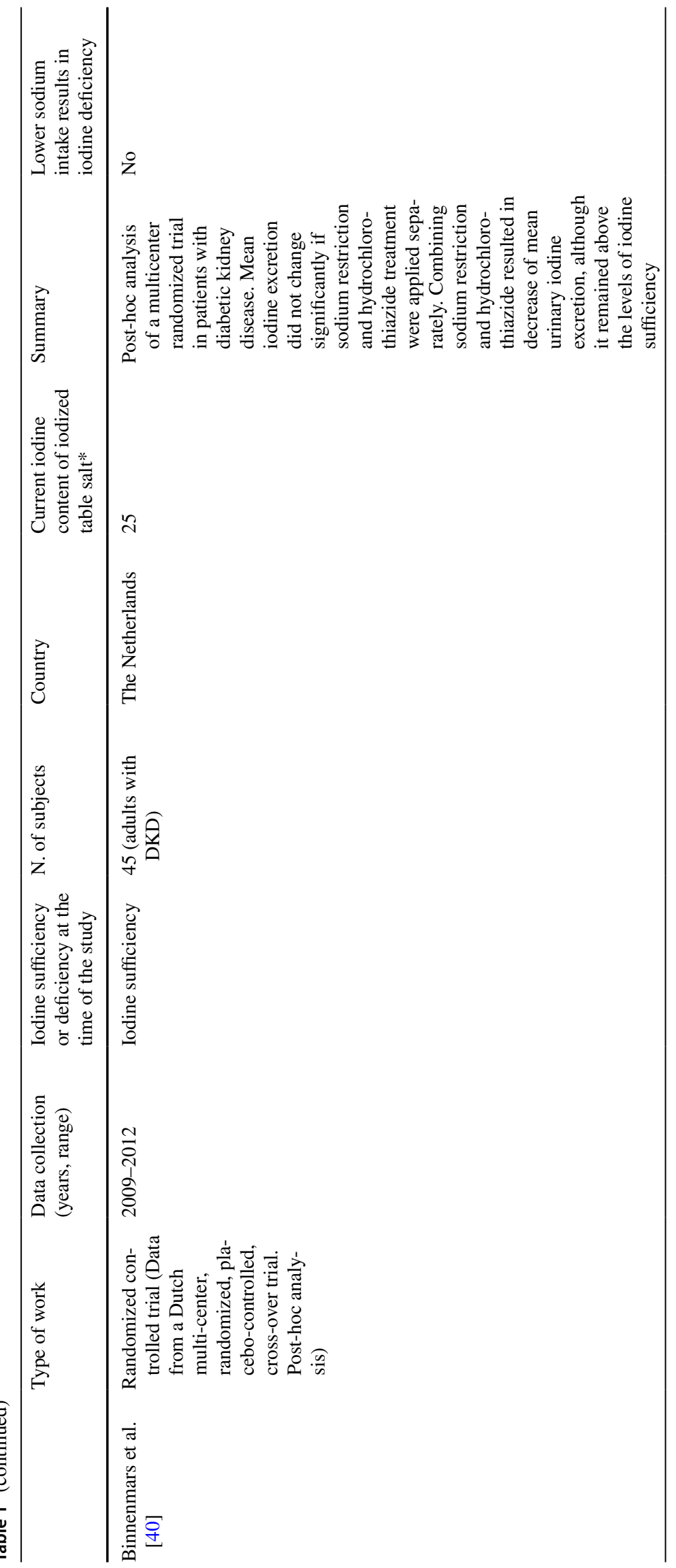




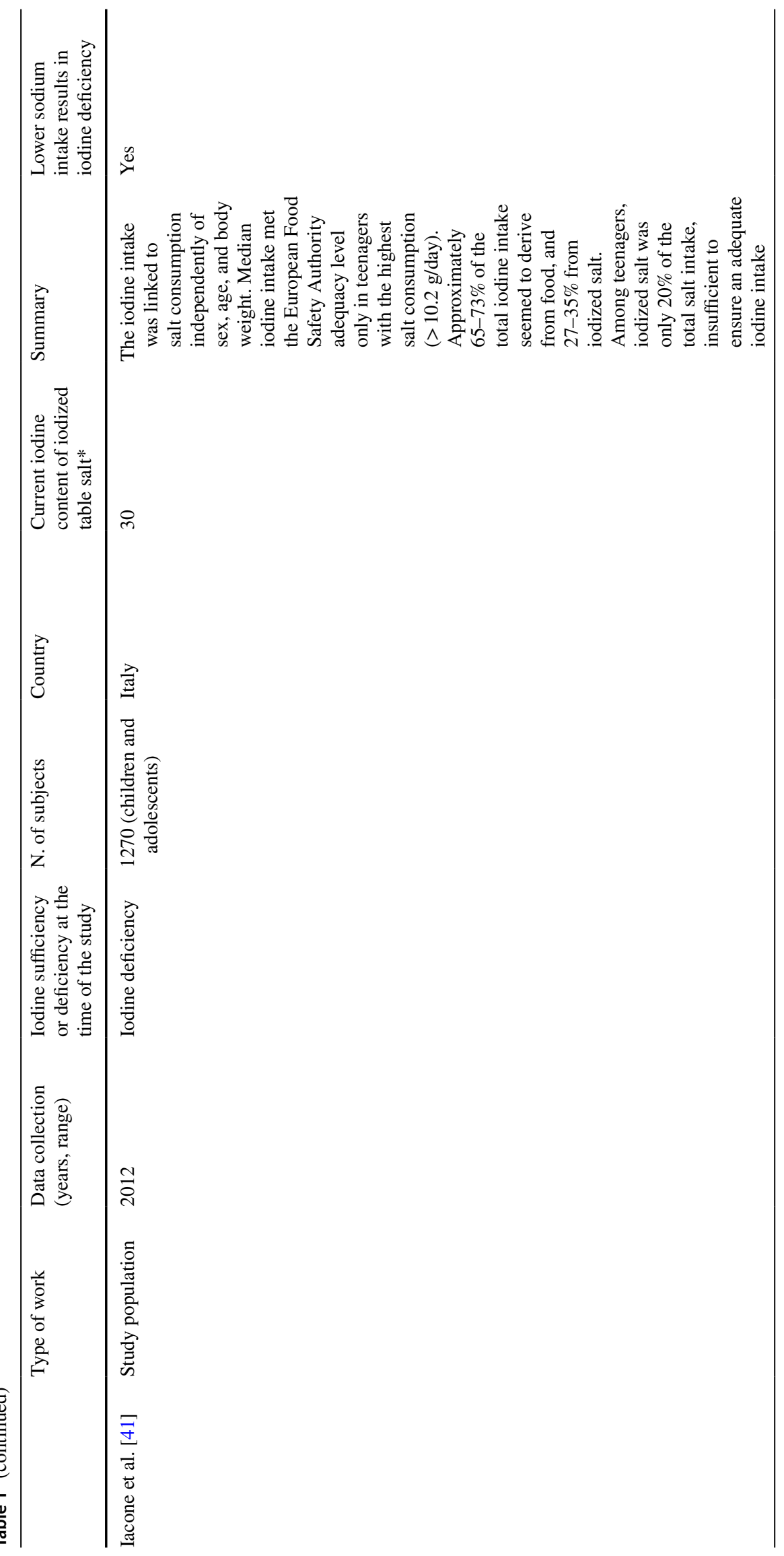




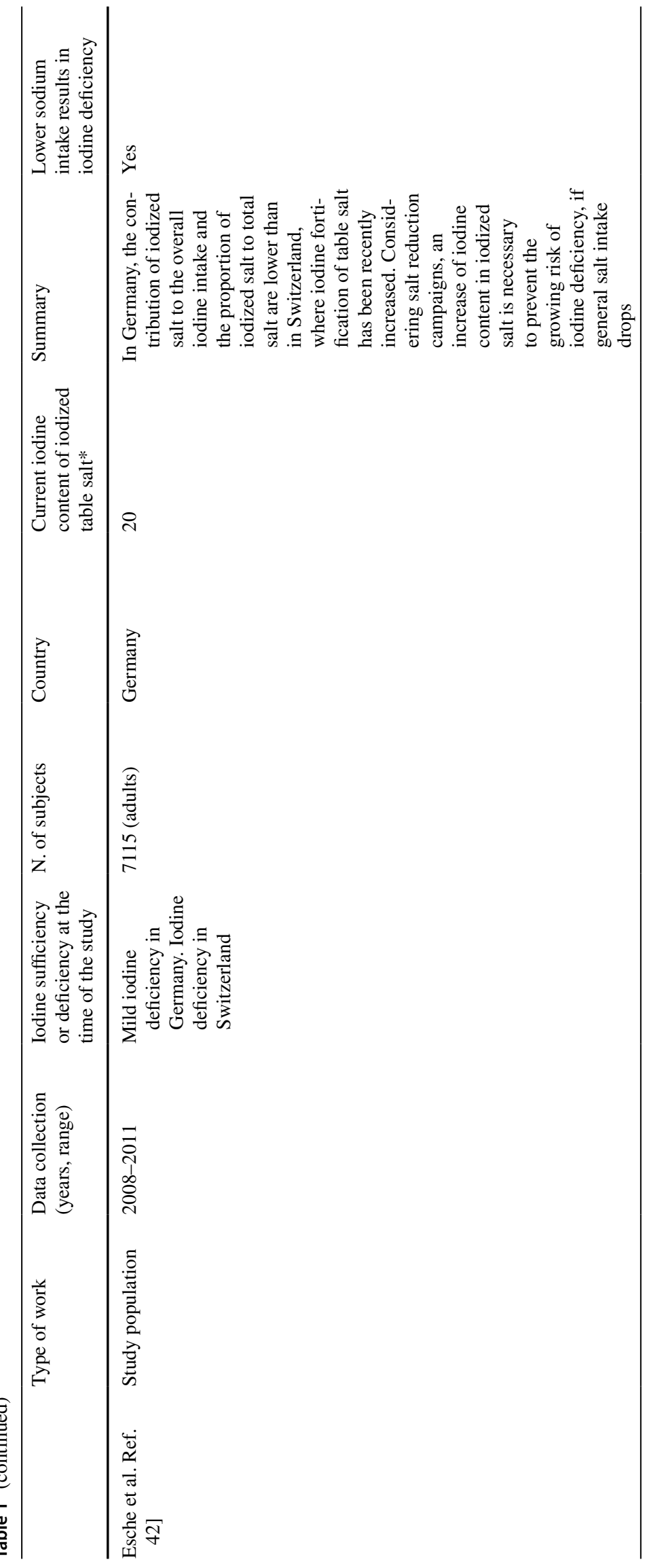


Journal of Endocrinological Investigation

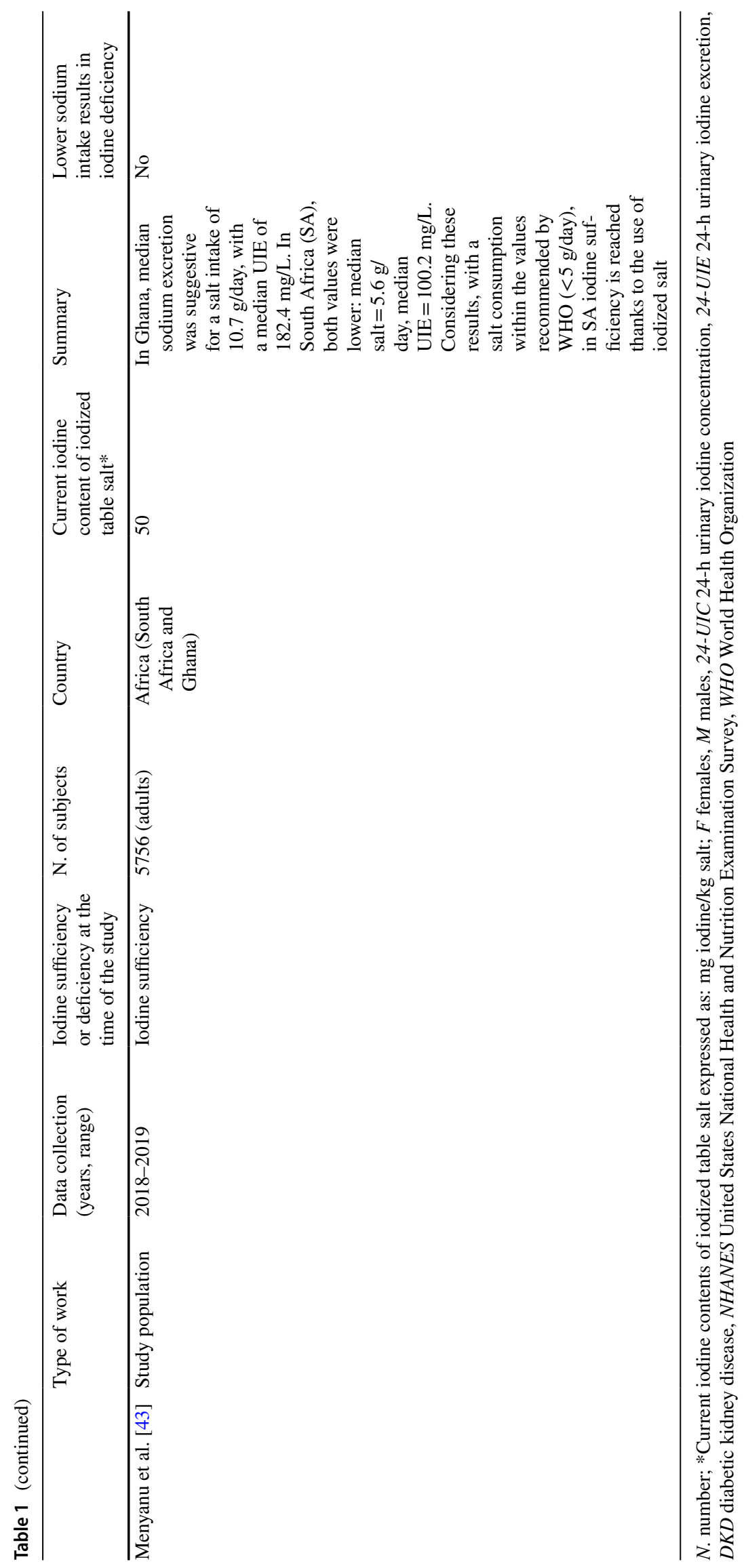

Springer 
Dietary sodium restriction is nowadays recommended by most guidelines in order to reduce the overall cardiovascular risk [1-4]. Furthermore, in the last years, many countries have pushed population-based initiatives highlighting the importance of salt reduction. Despite these recommendations, currently salt intake often exceeds the advised salt consumption due the misleading connection between salt preference and salt need [5]. Sodium is the primary component of table salt: sodium and salt are not interchangeable concepts, even if confusion still exists in the literature. Salt is sodium chloride, and its weight is approximately 2.54 times the weight of sodium alone. Sodium reduction, as suggested by International Guidelines [1-4], does not seem to induce iodine deficiency when the iodine status of the population evaluated is within the normal range (urinary concentration: $100-199 \mu \mathrm{g} / \mathrm{L} ; 24-\mathrm{h}$ UIE $=150$ to $300 \mu \mathrm{g} /$ day) [23]. Bearing in mind this background, whether a low sodium diet can induce iodine deficiency is matter of debate. To date, only few studies in the literature have focused on the topic concerning dietary sodium restriction, as recommended by International Organizations, and the possible interaction with the iodine status. A number of different reasons have led to the heterogeneity in the results reported and summarized in Table 1.

Firstly, studies have been carried out in both developing and developed countries, characterized by major differences in iodine status and sodium supply. Moreover, data have been recorded in a large span of time, while the iodine status is rapidly evolving in different ways in the various countries worldwide. These differences depend in a significant part upon prevention strategies, namely iodine content of iodized salt, universal use of iodized table salt, as well as the use of iodized salt in food industry and in bread-making process. Notably, the policies for universal iodized salt prophylaxis vary considerably in each country. Furthermore, the introduction of salt iodization policies does not necessarily imply a successfully operating iodized salt program. In detail, considering Europe, few countries have introduced compulsory enforcement of iodized salt and in 2018 the "Krakow Declaration on Iodine" endorsed the importance of stronger legislations to improve iodine status in Europe through mandatory iodization of table salt [44]. Concerning different scenarios outside Europe, in the US the great majority of dietary sodium derives from salt added in processed food and restaurants, overcoming the recommended sodium intake. Iodized salt was introduced in 1924 and subsequently the US Food and Drug Administration strained the importance of domestic iodized salt containing about $77 \mu \mathrm{g}$ of iodine at the production level [20], as shown in Table 1. In China universal salt iodization program was started in 1995 [27]. Conversely, for the Pacific region, less clear information is available concerning the level of salt consumption (iodized vs non-iodized) and the data on iodine nutrition.
Furthermore, the design of the different studies is widely heterogeneous, and it is worth highlighting that in the present analysis, we included 3 reports based on a simulation model [33, 36, 37].

Other aspects that make the results hard to compare are the different characteristics of the study groups. Among the studies assessed, children, adolescents, and adults were evaluated: it has been underlined that the choice of a specific target age group is critical, and other variables, such as the body mass index (BMI), may also play a role [45, 46]. As mentioned above, epidemiological surveys dealing with highly selected categories (including pregnant women) were not considered in the present analysis. Considering people undergoing special diets, it is worth citing the Paleolithictype diet, characterized by the exclusion of grains, legumes, dairy products, refined sugar, processed oils, and overall salt. This is a type of alimentary regimen linked with a higher risk of developing iodine deficiency [13] and iodine supplementation should be considered when on it.

Overall, the main issues affecting the interpretation of the results obtained from the various studies are both salt (and therefore sodium) and iodine dietary sources, which are deeply different around the world. In this context, the salt employed in the food industry represents a further important issue. Main iodine sources are "natural" food and water, as well as iodine-supplemented food and salt [47]. In some countries, iodine status seems to be sufficient, while in others, it is not [15, 31]. Of note, iodine excess can be also found, mostly due to high iodine content in tap water [48-51]. In many countries (Continental Europe, the UK and the US), the primary sources of iodine are dairy products and fortified table salt [52-57]. Elsewhere, especially in the Middle East, dietary iodine mainly comes from fortified flour and salt [58]. The single most important source of iodine is represented by fortified table salt in several areas, mainly Africa and Asia-Pacific Region [59-67]. In these latter regions, particularly in the developing countries, the availability and the use of fortified salt are strongly recommended, even if the availability itself may represent a major issue.

Dietary sources of sodium are variable, as well. Dietary sodium is usually higher than ideal and multiple dietary sources of sodium are available worldwide $[68,69]$. It is worth distinguishing the discretionary and non-discretionary salt intake. Indeed, we can identify countries primarily characterized by the habit of adding salt to the food while cooking or at table (discretionary salt), others by a daily and heavily consumption of packaged foods (a great amount of non-discretionary salt other than that naturally present in food), and those where the two quotes of salt intake are fairly balanced. In this scenario, a crucial point is the use of iodized salt by the food processing industry and by the catering sector. Indeed, when the industry employs fortified 
salt for preserved foods, and these products are one of the primary sources of sodium, the restrictions of table salt will not lead to iodine deficiency. Conversely, when the industry avoids the use of fortified salt in the preparation of packaged foods, a low sodium diet might be linked with a reduction of iodine intake in the population. Therefore, the use of iodized salt by the food industry and by the public catering sector (such as restaurants, children care centers and canteens) has been implemented over the last decade, with the aim of achieving an adequate iodine intake, even in the context of a reduction of discretionary salt.

Overall, there is an obvious relationship between salt consumption and iodine intake via iodized salt. The question arises as whether salt restriction may result in a lack of iodine supply, or not. It is conceivable that, when iodine deficiency is eradicated, iodine content of iodized salt is adequate, and iodized salt consumption is widespread, salt restriction does not impact at all the iodine status in general population. This point of view has been very recently emphasized in an "opinion" authored on behalf of various scientific societies [70]. Indeed, this position is supported by the results of the present systematic review, since we found that salt restriction favored iodine deficiency only in those countries where a stable condition of adequate iodine supply was not achieved [42]. Indeed, salt restriction resulted in less-than-adequate iodine supply in countries where iodine content of fortified salt was relatively low $(<30$ parts per million) [33, 42].

In any case, more attention is required for special at-risk groups, with marked reference to pregnant women, newborns, and children. Overall, programs aimed to achieve both salt intake reduction and increased salt iodization should go hand in hand, with a set monitoring to ensure a sufficient iodine intake [71].

Due to the primary relevance of optimal sodium intake, as well as iodine supply, further updated prospective studies on the effects of salt restriction on iodine status are required. Anyhow, there is no doubt that a proper monitoring of iodoprophylaxis is mandatory, to ensure a sustained adequate iodine supply, and to avoid iodine excess, a possible risk of uncontrolled iodine prophylaxis, that may result in an increased incidence of thyroid autoimmunity [71-73].

As a final joke, it is possible to recall the fundamental advice of some Italian scientific societies, when they recommend eating "poco sale, ma iodato" (only a bit of salt, but iodized) [74].

\section{Conclusion}

Since UNICEF has defined iodine deficiency "the single greatest cause of preventable mental retardation" and set the goal of virtual elimination of iodine deficiency disorders, it is worth underling the importance of iodized salt [75]. At the same time, excessive salt intake is a cause of chronic diseases, such as hypertension and cardiovascular diseases [76]. In this scenario, it is crucial to ensure a balance between iodine salt fortification without exceeding the current recommendation by WHO for a salt intake of $<5 \mathrm{~g} /$ day. This may be achieved by promoting worldwide a generalized availability of iodized salt for household consumption and food industry use, and by ensuring an adequate iodine concentration in fortified salt. However, considering both the strength to reach iodine sufficiency worldwide and the endorsed importance of a low sodium intake recommended by international institutions in the last years, it appears reasonable to call for a cooperation among countries to design prospective studies with a view to reaching comparable results and a definitive conclusion on this public health issue.

Acknowledgements The authors thank Antonella Olivieri* for her helpful comments that improved the manuscript. *Department of Cardiovascular and Endocrine-Metabolic Diseases and Aging, Italian National Institute of Health, Responsible for the Italian National Observatory for Monitoring Iodine Prophylaxis, Rome, Italy.

Author contributions Conceptualization: FN, NM and MB; Methodology: DF; Formal analysis and Investigation: FG, MA, FN, LV; Writing-original draft preparation: FN, NM and MB; Writing-review and editing: FG, LV, MA and MB; Supervision, DF, FG and MB. All authors have read and approved the final manuscript.

Funding No founds, grants, or other support was received for the preparation of this manuscript.

\section{Declarations}

Conflict of interest Diego Ferone has been a speaker for and participated on advisory boards and received research grants from Novartis, Ipsen and Pfizer. Diego Ferone is a member of the Editorial Board of Journal of Endocrinological Investigation. Federico Gatto has been a speaker for Novartis and has participated on advisory boards of Novartis, AMCo Ltd, and IONIS Pharmaceuticals. Diego Ferone and Manuela Albertelli are members of the Editorial Board of the Journal of Endocrinological Investigation. The other Authors have no conflicts of interest to declare.

Ethical approval This article does not contain any study with human participants and animals performed by any of the authors.

Informed consent As the present study is a review article no informed consent is required.

\section{References}

1. James PA, Oparil S, Carter BL et al (2014) 2014 Evidence-based guideline for the management of high blood pressure in adults: report from the panel members appointed to the eighth joint national committee (JNC 8). JAMA 311(5):507-520. https://doi. org/10.1001/jama.2013.284427 
2. Van Horn L, Carson JAS, Appel LJ et al (2016) Recommended dietary pattern to achieve adherence to the American Heart Association/American College of Cardiology (AHA/ACC) Guidelines: A scientific statement from the American Heart Association. Circulation 134(22):e505-e529. https://doi.org/10.1161/CIR.00000 00000000462

3. Whelton PK, Carey RM, Aronow WS et al (2018) 2017 ACC/ AHA/AAPA/ABC/ACPM/AGS/APhA/ASH/ASPC/NMA/PCNA Guideline for the prevention, detection, evaluation, and management of high blood pressure in adults: executive summary: a report of the american college of cardiology/american heart association task force on clinical practice guidelines. Hypertension 71(6):1269-1324. https://doi.org/10.1161/HYP.0000000000 000066

4. Williams B, Mancia G, Spiering W et al (2018) 2018 ESC/ESH guidelines for the management of arterial hypertension. Eur Heart J 39(33):3021-3104. https://doi.org/10.1093/eurheartj/ehy339

5. Kotchen TA, Cowley AW Jr, Frohlich ED (2013) Salt in Health and Disease - A Delicate Balance. N Engl J Med 368(13):12291237. https://doi.org/10.1056/NEJMra1212606

6. Strazzullo P, D'Elia L, Kandala NB, Cappuccio FP (2009) Salt intake, stroke, and cardiovascular disease: Meta-analysis of prospective studies. BMJ 339:b4567. https://doi.org/10.1136/bmj. b4567

7. He FJ, MacGregor GA (2011) Salt reduction lowers cardiovascular risk: Meta-analysis of outcome trials. Lancet 378(9789):380 382. https://doi.org/10.1016/S0140-6736(11)61174-4

8. Taylor RS, Ashton KE, Moxham T et al (2011) Reduced dietary salt for the prevention of cardiovascular disease: A meta-analysis of randomized controlled trials (Cochrane review). Am J Hypertens 24(8):843-853. https://doi.org/10.1038/ajh.2011.115

9. Bram B, Huang X, Cupples WA, Hamza SM (2017) Understanding the two faces of low-salt intake. Curr Hypertens Rep 19(6):49. https://doi.org/10.1007/s11906-017-0744-z

10. Graudal N, Jurgens G, Baslund B, Alderman MH (2014) Compared with usual sodium intake, low- and excessive-sodium diets are associated with increased mortality: A meta-analysis. Am J Hypertens 27(9):1129-1137. https://doi.org/10.1093/ajh/hpu028

11. O'Donnell M, Mente A, Rangarajan S et al (2014) Urinary sodium and potassium excretion, mortality, and cardiovascular events. $\mathrm{N}$ Engl J Med 371:612-623. https://doi.org/10.1056/NEJMoa1311 889

12. Oparil S (2014) Low sodium intake-Cardiovascular health benefit or risk? N Engl J Med 371:677-679. https://doi.org/10.1056/ NEJMe1407695

13. Manousou S, Stål M, Larsson C et al (2018) A Paleolithic-type diet results in iodine deficiency: a 2-year randomized trial in postmenopausal obese women. Eur J Clin Nutr 72(1):124-129. https:// doi.org/10.1038/ejen.2017.134

14. Kimball OP (1928) Endemic goiter and public health. Am J Public Health Nations Health 18(5):587-601. https://doi.org/10.2105/ ajph.18.5.587

15. Iodine Global Network (2021) Global Scorecard of Iodine Nutrition in 2020 in the General Population Based on Schoolage Children. Ottawa, Canada: IGN. https://www.ign.org/scorecard.htm. Accessed 13 Dec. 2021

16. Lazarus JH (2014) Iodine status in Europe in 2014. Eur Thyroid J 3(1):3-6. https://doi.org/10.1159/000358873

17. Olivieri A, Di Cosmo C, De Angelis S et al (2017) Regional observatory for goiter prevention. The way forward in Italy for iodine. Minerva Med 108(2):159-168. https://doi.org/10.23736/ S0026-4806.17.04877-7

18. Laurberg P, Cerqueira C, Ovesen L et al (2010) Iodine intake as a determinant of thyroid disorders in populations. Best Pract Res Clin Endocrinol Metab 24(1):13-27. https://doi.org/10.1016/j. beem.2009.08.013
19. World Health Organization (2014) Salt reduction and iodine fortification strategies in public health: report of a joint technical meeting convened by the world health organization and the George institute for global health in collaboration with the international council for the control of iodine deficiency disorders global network, Sydney, Australia. https://apps.who.int/iris/handle/10665/ 101509. Accessed 13 Dec. 2021

20. Tayie FA, Jourdan K (2010) Hypertension, dietary salt restriction and iodine deficiency among adults. Am J Hypertens 23(10):1095-1102. https://doi.org/10.1038/ajh.2010.120

21. Pearce EN, Andersson M, Zimmermann MB (2013) Global iodine nutrition: where do we stand in 2013? Thyroid 23(5):523-528. https://doi.org/10.1089/thy.2013.0128

22. Konig F, Andersson M, Hotz K et al (2011) Ten repeat collections for urinary from spot samples or 24-hour samples are needed to reliably estimate individual iodine status in women. J Nutr 141(11):2049-2054. https://doi.org/10.3945/jn.111.144071

23. Perrine CG, Cogswell ME, Swanson CA et al (2014) Comparison of population iodine estimates from 24-hour urine and timed-spot urine samples. Thyroid 24(4):748-757. https://doi.org/10.1089/ thy.2013.0404

24. Ji C, Lu T, Dary O et al (2015) Systematic review of studies evaluating urinary iodine concentration as a predictor of 24 hour urinary iodine excretion for estimating population iodine intake. Rev Panam Salud Publica 38(1):73-81

25. Conkle J, van der Haar F (2017) The use and interpretation of sodium concentrations in casual (spot) urine collections for popu-lation surveillance and partitioning of dietary iodine intake sources. Nutrients 9(1):7. https://doi.org/10.3390/nu9010007

26. Simpson FO, Thaler BI, Paulin J et al (1984) Iodide excretion in a salt-restriction trial. N Z Med J 97(770):890-893

27. He FJ, Ma Y, Feng X et al (2016) Effect of salt reduction on iodine status assessed by 24 hour urinary iodine excretion in children and their families in northern China: A substudy of a cluster randomised controlled trial. BMJ Open 6(9):e011168. https://doi.org/ 10.1136/bmjopen-2016-011168

28. Vega-Vega O, Fonseca-Correa JI, Mendoza-De la Garza A et al (2018) Contemporary dietary intake: Too much sodium, not enough potassium, yet sufficient iodine: The SALMEX Cohort study. Nutrients 10(7):816. https://doi.org/10.3390/nu10070816

29. Charlton K, Ware LJ, Baumgartner J et al (2018) How will South Africa's mandatory salt reduction policy affect its salt iodisation programme? A cross-sectional analysis from the WHO-SAGE Wave 2 Salt \& Tobacco study. BMJ Open 8(3):e020404. https:// doi.org/10.1136/bmjopen-2017-020404

30. Ershow AG, Skeaff SA, Merkel JM, Pehrsson PR (2018) Development of databases on iodine in foods and dietary supplements. Nutrients 10(1):100. https://doi.org/10.3390/nu10010100

31. Krela-Kaźmierczak I, Czarnywojtek A, Skoracka K et al (2021) Is there an ideal diet to protect against iodine deficiency? Nutrients 13(2):513. https://doi.org/10.3390/nu13020513

32. Moher D, Liberati A, Tetzlaff J, Altman DG, The PRISMA Group (2009) Preferred reporting items for systematic reviews and metaanalyses: The PRISMA statement. PLoS Med 6(7):e1000097. https://doi.org/10.1371/journal.pmed.1000097

33. Verkaik-Kloosterman J, van't Veer P, Ocké MC, (2010) Reduction of salt: will iodine intake remain adequate in The Netherlands? $\mathrm{Br}$ J Nutr 104(11):1712-1718. https://doi.org/10.1017/S000711451 0002722

34. Charlton KE, Jooste PL, Steyn K, Levitt NS, Ghosh A (2013) A lowered salt intake does not compromise iodine status in Cape Town, South Africa, where salt iodization is mandatory. Nutrition 29(4):630-634. https://doi.org/10.1016/j.nut.2012.09.010

35. Charlton K, Land MA, Ma G, Yeatman H, Houweling F (2014) Iodine status similarly suboptimal in Australian women who have desirable salt intakes compared to those with excessive 
intakes. Nutrition 30(2):234-235. https://doi.org/10.1016/j.nut. 2013.05.009

36. Pastorelli AA, Stacchini P, Olivieri A (2015) Daily iodine intake and the impact of salt reduction on iodine prophylaxis in the Italian population. Eur J Clin Nutr 69(2):211-215. https://doi. org/10.1038/ejen.2014.206

37. McMahon E, Webster J, O'Dea K, Brimblecombe J (2015) Dietary sodium and iodine in remote Indigenous Australian communities: will salt-reduction strategies increase risk of iodine deficiency? A cross-sectional analysis and simulation study. BMC Public Health 15:1318. https://doi.org/10.1186/ s12889-015-2686-1

38. Land MA, Webster JL, Ma G et al (2016) Salt intake and iodine status of women in Samoa. Asia Pac J Clin Nutr 25(1):142-149. https://doi.org/10.6133/apjen.2016.25.1.09

39. Musso N, Conte L, Carloni B et al (2018) Low-salt intake suggestions in hypertensive pa-tients do not jeopardize urinary iodine excretion. Nutrients 10(10):1548. https://doi.org/10.3390/nu101 01548

40. Binnenmars SH, Corpeleijn E, Kwakernaak AJ et al (2019) Impact of moderate sodium restriction and hydrochlorothiazide on iodine excretion in diabetic kidney disease: data from a ran-domized cross-over trial. Nutrients 11(9):2204. https://doi.org/10.3390/ nu11092204

41. Iacone R, Iaccarino Idelson P, Campanozzi A et al (2020) MINISAL-GIRCSI Study Group. Relationship between salt consumption and iodine intake in a pediatric population. Eur J Nutr 60(4):2193-2202. https://doi.org/10.1007/s00394-020-02407-w

42. Esche J, Thamm M, Remer T (2020) Contribution of iodized salt to total iodine and total salt intake in Germany. Eur J Nutr 59(7):3163-3169. https://doi.org/10.1007/s00394-019-02154-7

43. Menyanu E, Corso B, Minicuci N et al (2020) Salt-reduction strategies may compromise salt iodization programs: Learnings from South Africa and Ghana. Nutrition 84:111065. https://doi.org/10. 1016/j.nut.2020.111065

44. Vila L, Puig-Domingo M (2018) The Krakow declaration: The last chance for Europe to eradicate iodine deficiency. Endocrinol Diabetes Nutr 65(10):553-555. https://doi.org/10.1016/j.endinu. 2018.10.001

45. Lazarus JH (2021) Monitoring iodine nutritional status: adults or schoolchildren? J Endocrinol Invest 44(2):383-385. https://doi. org/10.1007/s40618-020-01313-6

46. De Angelis S, Bagnasco M, Moleti M, Regalbuto C, Tonacchera $\mathrm{M}$, Vermiglio $\mathrm{F}$ et al (2021) Obesity and monitoring iodine nutritional status in schoolchildren: Is body mass index a factor to consider? Thyroid 31(5):829-840. https://doi.org/10.1089/thy. 2020.0189

47. Miller V, Singh GM, Onopa J et al (2021) Global Dietary Database 2017: data availability and gaps on 54 major foods, beverages and nutrients among 5.6 million children and adults from 1220 surveys worldwide. BMJ Glob Health 6(2):e003585. https://doi. org/10.1136/bmjgh-2020-003585

48. Gao M, Chen W, Dong S et al (2021) Assessing the impact of drinking water iodine concentrations on the iodine intake of Chinese pregnant women living in areas with restricted iodized salt supply. Eur J Nutr 60(2):1023-1030. https://doi.org/10.1007/ s00394-020-02308-y

49. Saha S, Abu BAZ, Jamshidi-Naeini $Y$ et al (2019) Is iodine deficiency still a problem in sub-Saharan Africa?: a review. Proc Nutr Soc 78(4):554-566. https://doi.org/10.1017/S0029665118002859

50. Li S, Zheng Q, Xu J et al (2011) Iodine excess or not: analysis on the necessity of reducing the iodine content in edible salt based on the national monitoring results. Asia Pac J Clin Nutr 20(4):501-506

51. Kassim IA, Moloney G, Busili A et al (2014) Iodine intake in Somalia is excessive and associated with the source of household drinking water. J Nutr 144(3):375-381. https://doi.org/10.3945/ jn.113.176693

52. Szybiński Z, Jarosz M, Hubalewska-Dydejczyk A et al (2010) Iodine-deficiency prophylaxis and the restriction of salt consumption - a 21st century challenge. Endokrynol Pol 61(1):135-140

53. Perrine CG, Herrick K, Serdula MK, Sullivan KM (2010) Some subgroups of reproductive age women in the United States may be at risk for iodine deficiency. J Nutr 140(8):1489-1494. https:// doi.org/10.3945/jn.109.120147

54. Watutantrige-Fernando S, Barollo S, Bertazza L et al (2018) Efficacy of educational intervention to improve awareness of the importance of iodine, use of iodized salt, and dietary iodine intake in northeastern Italian schoolchildren. Nutrition 53:134-139. https://doi.org/10.1016/j.nut.2018.02.010

55. Censi S, Manso J, Barollo S et al (2020) Changing dietary habits in veneto region over two decades: still a long road to go to reach an io-dine-sufficient status. Nutrients 12(8):2399. https://doi.org/ 10.3390/nu12082399

56. Torres MT, Vila L, Manresa JM et al (2020) Impact of dietary habit, iodine supplementation and smoking habit on urinary iodine concentration during pregnancy in a catalonia population. Nutrients 12(9):2656. https://doi.org/10.3390/nu12092656

57. Threapleton DE, Waiblinger D, Snart CJP et al (2021) Prenatal and postpartum maternal iodide intake from diet and supplements, urinary iodine and thyroid hormone concentrations in a region of the united kingdom with mild-to-moderate iodine deficiency. Nutrients 13(1):230. https://doi.org/10.3390/nu13010230

58. Massad S, Gebre-Medhin M, Dary O et al (2020) Micronutrient status of Palestinian school children following salt and flour fortification: a cross-sectional study. BMC Nutr 6:38. https://doi. org/10.1186/s40795-020-00367-2.eCollection2020

59. Saborido L, Latres de Rauek B, Rezzónico JN et al (1996) Iodine in school children. Relationship with incidence of goiter, socioeconomic group and salt intake. Medicina (B Aires) 56(5 Pt 1):448-454

60. Yamada C, Oyunchimeg D, Erdenbat A et al (2000) Estimation of salt intake and recommendation for iodine content in iodized salt in Mongolia. Asia Pac J Public Health 12(1):27-31. https:// doi.org/10.1177/101053950001200106

61. Thomson BM, Vannoort RW, Haslemore RM (2008) Dietary exposure and trends of exposure to nutrient elements iodine, iron, selenium and sodium from the 2003-4 New Zealand Total Diet Survey. Br J Nutr 99(3):614-625. https://doi.org/10.1017/S0007 114507812001

62. Basu S, Stuckler D, Vellakkal S, Ebrahim S (2012) Dietary salt reduction and cardiovascular disease rates in India: a mathematical model. PLoS ONE 7(9):e44037. https://doi.org/10.1371/journ al.pone. 0044037

63. Campbell NR, Dary O, Cappuccio FP et al (2012) Need for coordinated programs to improve global health by optimizing salt and iodine intake. Rev Panam Salud Publica 32(4):281-286. https:// doi.org/10.1590/s1020-49892012001000006

64. Ovadia YS, Arbelle JE, Gefel D et al (2017) First israeli national iodine survey demonstrates iodine deficiency among school-aged children and pregnant women. Thyroid 27(8):1083-1091. https:// doi.org/10.1089/thy.2017.0251

65. Al-Dakheel MH, Haridi HK, Al-Bashir BM et al (2018) Assessment of household use of iodized salt and adequacy of salt iodization: a cross-sectional National Study in Saudi Arabia. Nutr J 17(1):35. https://doi.org/10.1186/s12937-018-0343-0

66. Dold S, Zimmermann MB, Jukic T et al (2018) Universal salt iodization provides sufficient dietary iodine to achieve adequate iodine nutrition during the first 1000 days: a cross-sectional multicenter study. J Nutr 148(4):587-598. https://doi.org/10.1093/jn/nxy015

67. Vega-Vega O, Fonseca-Correa JI, Mendoza-De la Garza A et al (2018) Contemporary dietary intake: too much sodium, not 
enough potassium, yet sufficient iodine: The SALMEX cohort results. Nutrients 10(7):816. https://doi.org/10.3390/nu10070816

68. Powles J, Fahimi S, Micha R et al (2013) Global, regional and national sodium intakes in 1990 and 2010: a systematic analysis of $24 \mathrm{~h}$ urinary sodium excretion and dietary surveys worldwide. BMJ Open 3(12):e003733. https://doi.org/10.1136/bmjop en-2013-003733

69. Elliott P, Brown I (2006) Sodium intakes around the world. Background document prepared for the Forum and Technical meeting on Reducing Salt Intake in Populations. World Health Organization, Paris, France. https://apps.who.int/iris/handle/10665/43738 Accessed 13 Dec. 2021

70. Olivieri A, Giorgino F, Maffeis C, Bagnasco M (2021) Salt reduction and iodine intake in Italy. J Endocrinol Invest. https://doi.org/ 10.1007/s40618-021-01708-Z

71. Olivieri A, Trimarchi F, Vitti P (2020) Global iodine nutrition 2020: Italy is an iodine sufficient country. J Endocrinol Invest 43:1671-1672. https://doi.org/10.1007/s40618-020-01402-6
72. Teti C, Panciroli M, Nazzari E et al (2021) Iodoprophylaxis and thyroid autoimmunity: an update. Immunol Res 69(2):129-138. https://doi.org/10.1007/s12026-021-09192-6

73. Ruggeri RM, Trimarchi F (2021) Iodine nutrition optimization: are there risks for thyroid autoimmunity? J Endocrionol Invest 44(9):1827-1835. https://doi.org/10.1007/s40618-021-01548-x

74. https://www.salute.gov.it/portale/documentazione/p6_2_5_1.jsp? lingua $=$ italiano\&id=18. Accessed 13 Dec. 2021

75. UNICEF (2008) Sustainable elimination of iodine deficiency. https://data.unicef.org/resources/sustainable-elimination-ofiodine-deficiency/ Accessed 13 Dec. 2021

76. GBD 2017 Diet Collaborators (2019) Health effects of dietary risks in 195 countries, 1990-2017: a systematic analysis for the Global Burden of Disease Study 2017. Lancet 393(10184):1958 1972. https://doi.org/10.1016/S0140-6736(19)30041-8

Publisher's Note Springer Nature remains neutral with regard to jurisdictional claims in published maps and institutional affiliations. 